\title{
KohaILS:AnEfficientOpenSourceApplicationof Integrated Library System
}

\author{
Suaad Yahaya Mohammed Ali ${ }^{1}$, Iman Osman Mukhtar Ahmed ${ }^{2}$, \\ Noor HasrulNizan Bin Mohammad Noor ${ }^{3}$ \\ ${ }^{1,3}$ Department of Library and Information Science, International Islamic University Malaysia \\ ${ }^{2}$ Department of Educational Psychology and Counseling, International Islamic University Malaysia \\ ${ }^{3 *}$ nhasrul@iium.edu.my
}

Article History: Received: 10 November 2020; Revised: 12 January 2021; Accepted: 27January 2021;

Published online: 05April 2021

\begin{abstract}
Most public and private libraries are inclined to adopt using Koha ILS around the globe. However, several Arab schools could not implement the Koha ILS application to automate their school libraries for ease of use. Deploying technology in managing libraries can solve several identified issues in public and private schools. This provides efficiency, ease and improves the performance of library services. Therefore, this paper is based on qualitative research that implements an efficient open-source application known as Koha ILS in two Arab schools, namely Baseerah International School (BIS) and International Modern Arab School (IMAS), Kuala Lumpur, Malaysia. In our analysis, we consider analyzing the proposed Koha ILS by providing backend accessibility so as library consumers can make a further enhancement to upgrade the application. The proposed Koha presents several positive impacts such as an efficient cataloging system, remote management of library consumer records such as books or room reservations and customizable searching interface for efficient usage. The application also presents multiple operating system support for a user's flexibility. In our results, an analysis was made by comparing the two schools based on gender, position/ranks available in the school library, and IT gadgets. Toward this end, some limitations were noted and recommended as a future research direction.
\end{abstract}

Keywords:Koha, integrated library system, cataloguing, gadgets

\section{Introduction}

Koha is an efficient and scalable library management system used in educational institutions. It remains the world's pioneer as an open-source and costless library system. Libraries of different forms support its development, and sizes, helpers, and companies around the globe. Koha integrated library system properties comprise of catalog, Circulation, staff Management and ownership packages. It is operated as a computer software installed on a Linux Server, Apache, MySQL, and Perl languages using commands on their command line or GUI interfaces. Katipo Communications created koha software in the year 1999 for Horowhenua trust in New Zealand. It is put to use by installation on personal computers in January 2000 [1].

The primary motivation of this research is that trademarked library application software is effectively in use but has a few limitations of a software update, security, lack of efficiency and scalability. These are some open issues that, when implemented, can efficiently enhance an integrated library system. Hence, our proposed implementation's main objective is to analyze the library consumers, staff, administrators' use and maintenance of Information technology tools. This work also aims to assess the technical standards of computers and other electronics in the library. A critical comparison of characteristics of some trademarked open source ILS for two selected International Arabic schools in Kuala Lumpur will also be conducted.

\subsection{Library}

A library is a collection of information resources and services. The resources are organized to be used by the public, an institution, or by an individual [1,2]. The importance of a library's integrated systems such as cataloging, circulation, acquisition and serials management is no longer debatable as libraries worldwide have realized the need to move from their manual practices to integrated systems or network operations. Prior to computerization, the library's tasks were performed manually and separately from one another Library Automation refers to the use of computers to serve the needs of library users[1,3].

The quality of a library operation jumps with the introduction of computers. Computers provide fast and reliable access to the resources available in the library as well as elsewhere. The application of computers in the library operations reduces repetitive jobs, saves much time, speeds up operations, and increases library resources. Computers are not only used as tools for processing data, but they are also employed for data storage. The opensource Integrated Library Management Software (ILMS) provides a planning system and various attractions for libraries. The open-source or the ILMS is used as Public license GPL according to their needs [4-6]. It is an effective source for developing countries to save money and balance the library budgets conversely, and 
proprietary library management software costs too much money for yearly maintenance. In-house developed software is also used for library management. It is specially made for library management like maintaining OPAC, or fostering acquisition, circulation, and other library operations.

Nowadays, open-source or ILMS is very common, particularly in developing countries, and general academic libraries are willing to adopt them. The advent of the Internet and the World Wide Web has not only brought a dramatic change in library's resources and materials, but it has also changed the way of providing library services and meeting users' expectations. The Koha system is a suitable application for schools' libraries, and it provides great benefits for students and attracts them to the library. This can prevent items from missing, such as books and other materials. Koha software is a user-friendly acquisition module of, advanced OPAC system, cataloging, circulation and serial management. The Koha ILS can provide all modern library services to their students, and the first implementation was in the Saudi School library. It recorded all results and challenges faced by the implementation process $[6,7]$.

Below is the record of libraries that adopted the use of the Koha library system in the united states.

$\begin{array}{lcc}\text { Support Option } & \text { Libraries } & \text { Facilities } \\ \text { ByWater Solutions } & 667 & 1,041 \\ \text { PTFSILibLime } & 223 & 515 \\ \text { Independent } & 80 & 128 \\ \text { Equinox } & 16 & 18 \\ \text { Combined } & 986 & 1,702 \\ \text { Total in libraries.org } & 997 & 1,714\end{array}$

Figure 1.Total number of libraries that implements Koha [1]

\subsection{Koha and Coral}

Another open-source library resource is the Coral. Coral software is also an open-source electronic resource management system. The inventor of Coral Hesburgh archives at the University of Notre Dame offered an extension to libraries archives and merchants worldwide to enhance the software as their contribution to meet the dynamic future developments [8]. Table 1 shows a comparison between Koha and Coral.

Table1.Comparison between Koha and Coral [5]

\begin{tabular}{|l|l|l|}
\hline & Koha & Coral \\
\hline Komponents & $\begin{array}{l}\text { Koha is an open-source integrated } \\
\text { library software resource }\end{array}$ & $\begin{array}{l}\text { Coral is an open-source electronic library } \\
\text { resource }\end{array}$ \\
\hline $\begin{array}{l}\text { Ownership, Categorization, mobile, } \\
\text { documentable }\end{array}$ & $\begin{array}{l}\text { Asset, organization, Trademarked with } \\
\text { license, Statistical. }\end{array}$ \\
\hline Resource Maintenance & Easily maintain using software & Easily maintain the electronic hardware \\
\hline e-resource maintenance & $\begin{array}{l}\text { Easily and user-friendly for all e- } \\
\text { applications }\end{array}$ & Very efficient across its modules \\
\hline Electronic subscription & Difficulty in maintenance & $\begin{array}{l}\text { e-applications are accessed using the } \\
\text { application components in CORAL }\end{array}$ \\
\hline Web Access & $\begin{array}{l}\text { Several languages can be used in } \\
\text { coding }\end{array}$ & Supports Limited languages in coding \\
\hline Prototype & Updatable & Updatable \\
\hline Integration & Can be integrated & Can be integrated \\
\hline
\end{tabular}

Several studies around the globe have been conducted on the open-source system of Koha. Koha is very crucial for user outlook; systems approach, and it is cost-effective. However, librarians recorded challenges when putting Koha to its implementation, such as less infrastructure and high costs. Other researchers [9-11] pointed out the implementation based on the user's outlook for library experts in Asia and that several libraries highly 
adopt its implementation. Other formats embedded in Koha are the new general library, which carries tremendous characteristics that enhance Koha's functionality [12, 13, 33]. Other researchers also perform analysis of an OSS such as Koha and New general library to inform librarians on the deliberations they ought to make in selecting a better OSS [34, 35]. Their results present the high efficiency of Koha as compared to new general library. Thus, Koha presents sophisticated characteristics such as better documentation, as well as userfriendly information download and installation procedures.

\subsection{Koha open source system}

The global market offers several open-source Koha systems such as Koha, Lucidea, Mandarin, OPALS, OpenBiblio, NewGenLib and Evergreen [14, 15]. Koha uses a general public license and adopted by several other countries in the USA, Australia and Asia. The OS is used by librarians in large, small, and medium-sized libraries. These can be classified as in schools, private homes, state or national libraries [16, 17]. The OS has several release versions and supports cataloging of machine-readable or the universal machine-readable.Figure 2. presents the wide acceptance of the use of the Koha application.

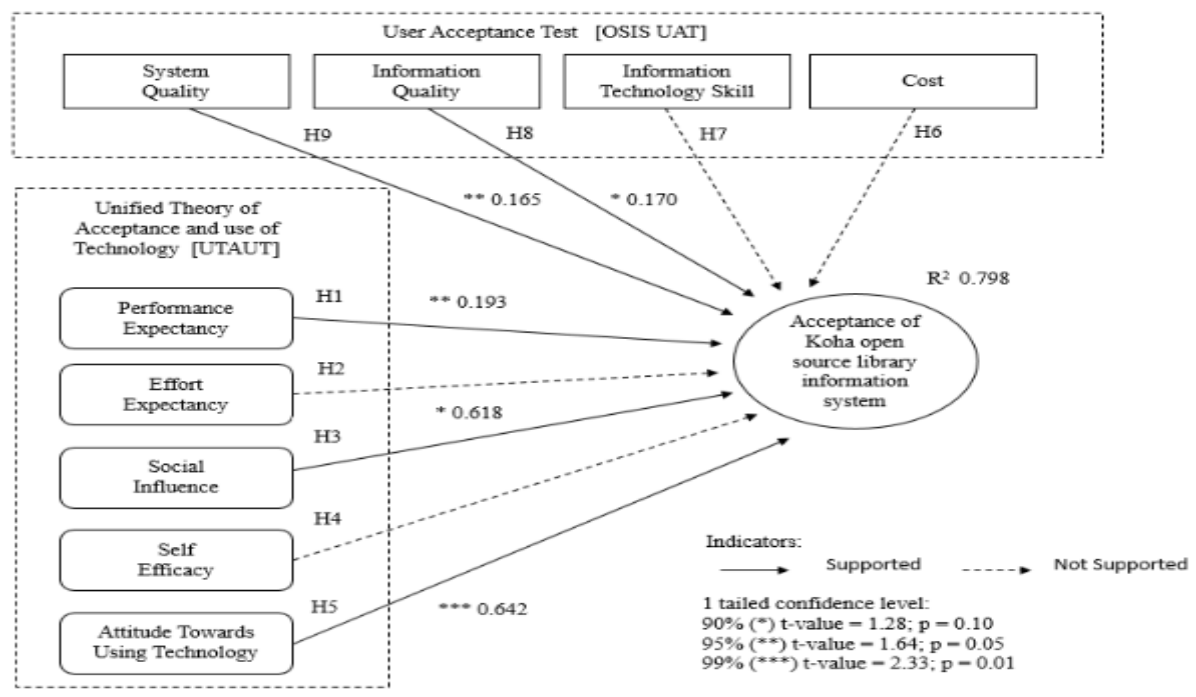

Figure 2.Adopted Framework for Koha Acceptability [25]

\subsection{Technology, System and the Users}

The major aspect of ensuring assessment is the technology user and system usage. The administrators' action has an effect when choosing implementation and system deployment.

\subsection{Integrated Library Systems in Open Libraries}

Gradually, open libraries no longer depend on wearing glasses following a well-ordered desk. Users use their entrance into the library using a technical device known as the computer screen. The time for adopting technology as an access pathway is the Pandora's box, which is a promising technique but may consist of some few issues and challenges [18]. Hence, to implement this technique in real scenarios, those in the field of Information Technology (IT) provide several findings from a simple to a complex solution such that library users can access anytime they engage in information seeking. A crucial choice that IT professionals implement is the Integrated Library System (ILS). ILS offers online access for the general public known as the OPAC. The (OPAC) Online Public Access Catalogue presents countless library abilities to librarians, managers and users. These functionalities impact data and information transmission during content presentation [19, 20, 30].

Work in $[6,21]$ explains that some of Koha's beneficial features comprise a simple interface, web 2.0 competencies, and customizable search. It was built using library standards and protocols that allow Koha to interact well with other existing workflows from different systems. Koha works using OPAC, and it is compliant with XHTML, CSS and JavaScript, making its platform-independent [22]. Koha is the enterprise resource planning system used for automating and integrating information management practices in an organization. Library patrons nowadays expect [23] faster service, service availability, and easy access. Virtual reference service is also possible with librarians available online always [24]. 
Easy-to-use Web resources permitting self-service. [25, 31, 32] defined an integrated library system as an interrelated suite of computer programs that automates multiple library operations. The papersdrawacademic librarians' attention to improve their knowledge and skills in Web technologies to design and implement services that would meet the changing needs of library users. As in [26],the software was used to assess the measurement and structural models. Several workshas been carried to guide the process of defining success for specific challenges on Koha research, as mentioned in [27-29].

Open-source library is well accepted in several cities of the united stated and even beyond such as Asia, Europe and Africa. Figure 3 shows some findings using open source system of the library in the United State of America.

\begin{tabular}{|c|c|c|c|}
\hline Libraries & Koha & Evergreen & OPALS \\
\hline Public & 126 & 58 & - \\
\hline Academic & 23 & - & 3 \\
\hline School & 32 & - & 51 \\
\hline Museum & 12 & - & - \\
\hline Medical & 3 & - & - \\
\hline Church & 2 & - & 2 \\
\hline Other special & 10 & - & 3 \\
\hline Total & 208 & 58 & 59 \\
\hline
\end{tabular}

Figure 3. Open Source System of library [3]

Moreover, an extensive review is further conducted to critically examine the related reviews concerning Koha ILS. This is shown in Table 2.

Table 2. Summary of Related Works

\begin{tabular}{|c|c|c|c|}
\hline Author & Contribution & Results & Limitation \\
\hline $\begin{array}{l}\text { Jabeen, Sumaira, } \\
(2020)\end{array}$ & $\begin{array}{l}\text { The paper investigates ILS's } \\
\text { role in academic environments } \\
\text { with particular reference to } \\
\text { koha because of its global } \\
\text { familiarity. }\end{array}$ & $\begin{array}{l}\text { Hypothetically } \\
\text { identified a few } \\
\text { solutions to the existing } \\
\text { Koha application to be } \\
\text { used in improving } \\
\text { academic libraries. }\end{array}$ & $\begin{array}{l}\text { States some limitations } \\
\text { of power and human } \\
\text { capacity development } \\
\text { when using Koha in } \\
\text { school libraries. }\end{array}$ \\
\hline $\begin{array}{l}\text { Kumar, } \\
(2019)\end{array}$ & $\begin{array}{l}\text { The paper analyzes to realize } \\
\text { the current approach of } \\
\text { automating the university } \\
\text { library using Koha in } \\
\text { Bangladesh. It also exploits } \\
\text { the phases of software } \\
\text { development, and cataloged } \\
\text { resources etc. }\end{array}$ & $\begin{array}{l}\text { Provided nine different } \\
\text { suggestions of policy } \\
\text { that can solve the issues } \\
\text { of using Koha software } \\
\text { in the university } \\
\text { libraries }\end{array}$ & $\begin{array}{l}\text { It could not cover all the } \\
\text { universities in } \\
\text { Bangladesh but suggest } \\
\text { the wide coverage as } \\
\text { ongoing research. }\end{array}$ \\
\hline $\begin{array}{l}\text { Mathar, } \\
(2020)\end{array}$ & $\begin{array}{l}\text { The paper analyzed the } \\
\text { migration or upgrading } \\
\text { process of Alauddin UIN } \\
\text { Library from manual to digital } \\
\text { approach. } \\
\text { Several failures were } \\
\text { encountered with the manual } \\
\text { approach, such as data } \\
\text { mobility, time, cost, and } \\
\text { capacity development. }\end{array}$ & $\begin{array}{l}\text { Have realized better } \\
\text { planning, simulation } \\
\text { and testing, migration, } \\
\text { data management, and } \\
\text { operation in the new } \\
\text { digitalized library } \\
\text { system }\end{array}$ & $\begin{array}{l}\text { They have implemented } \\
\text { Koha but still facing a } \\
\text { few challenges of } \\
\text { migration. }\end{array}$ \\
\hline $\begin{array}{l}\text { Asfand-E-Yar, M } \\
(2020)\end{array}$ & $\begin{array}{l}\text { The paper identifiesthree main } \\
\text { open issues of using Semantic } \\
\text { Heterogeneous Databases that }\end{array}$ & $\begin{array}{lcr}\text { Results } & \text { present } & \text { an } \\
\text { effective } & \text { and scalable } \\
\text { approach } & \text { to } & \text { its } \\
\end{array}$ & $\begin{array}{l}\text { Showed their approach } \\
\text { is still open for more } \\
\text { enhancements for future }\end{array}$ \\
\hline
\end{tabular}




\begin{tabular}{|l|l|l|l|}
\hline & $\begin{array}{l}\text { are directly implementable for } \\
\text { Koha, such as Semantic, } \\
\text { Syntactic and Structural } \\
\text { Heterogeneity. }\end{array}$ & & researchers. \\
\hline
\end{tabular}

\section{Research Method}

In this study, to develop an efficient open-source ILS, attention is centered on two International Arabic schools in Kuala Lumpur. These are Baseerah International School (BIS) and the International Modern Arab School (IMAS). An interview was conducted with the current school librarians. Both librarians emphasize the difficulty they face when managing their school library facilities. A significant issue was the lack of digital Information Technology devices. Another challenge is that items were not fully protected with a manual system. The librarians complained that many books were missing because there was no control system to check-in and check-out the books. Another issue that confronted them was fewer items in their libraries, but with the koha system, students could borrow books and return them using the online Koha system records. There was much control, and the koha has a user-friendly interface. They could get a donation from different places in the world. Many donors like to support schools' libraries in terms of giving books and other educational materials. Moreover, Basserah School did not have a specialized librarian.

Meanwhile, the library staff mentioned that students had two lectures perweek, but they did not find those lectures interesting because they were conducted traditionally using books.

\subsection{Analysis of Koha ILS}

The Koha system engineers the fast-growing ideas in developing libraries in our communities for user interaction or educational collaboration.Koha is a web-based system of ILS uses a Structural Query Language backend. This means it is an SQL application where the technical aspect cannot be read/write by a user, but the software aspect can be used for data and information manipulation and storage. The user's the edge/interface can be configured and deployed to be interpreted in several computer languages. The Koha system consists of excellent characteristics that are found in regular Integrated Library Services. These characteristics include Web2.0 such as tags, comments, shearing, timeline-feed, search tool, etc.

The characteristics of the proposed Koha system is designed and implemented as follows

- Accessible catalog for the public library: this offers web-based online access, which does not necessarily require software application to be installed in a user's computer device.

- Circulation edge: this is a web-based interface that maintains resource shearing and content reappearance. This does not require a global internet connection or software package to be installed on the management's personal computer but connects to a local switch or hub as an intranet communication.

- Management of Consumers records: this permits information manipulation of each library consumer with a valid membership.

- User's accessibility for resource reservation: the library user can remotely reserve a target resource online and can be able to renew his collection when his reservation window is expired. This ability will highly minimize the traffic found in the library management desk, thereby reducing staff workload.

- Custom search: this permits the web-based application to select any field to search from the website.

- Library to library MoU: this can be ensured when two or more public or private librarians sign a memorandum of understanding. Library users can virtually visit and use each other's resources and enjoy some benefits such as scholarships, internships, etc.

\subsection{Koha ILS Support}

The library automation using Koha Integrated Library System offers minimal cost of deployment and a userfriendly system. It has gained popularity around the globe, especially in Arab countries, African countries and even in the United States. This is because of its reliable services, enhanced performance, ease of collaboration and resource sharing. The application gives user autonomy when searching for vital resources in the library in books, journals, eBooks, research dissertations, and white papers. Autonomy enables library users to manipulate data and information during research analysis.

- Koha Reliability: the application software does not present any challenge when in use but always userfriendly. Data and information are always reliable without loss or failure. No form of bugs and when encountered, can have prompt fixes at the backend. 
- Koha Consistency and Stability: Software merchants from branded companies always ensure they promote their software application using upgrades with less effort. Sometimes, merchants offer their customers backend access to upgrade their Koha application when required. Based on reports, customers show a lot of appreciation for that open access.

- Koha Assessment: relative to Koha consistency, evaluating Koha using backend accessibility gives users liberty to observe the basic standard of Koha, including security and availability.

- Koha Cost: deploying the proposed application software to computers in the library is free. This adopts the standards of developing open software by computer experts and scientists. This is unlike branded software who attach a cost to their products.

\section{Result and Discussion}

In the results, gender is used to identify data distributions in the two schools. We use the same approach used in the benchmark in Table 1, 2 and 3. Below are the proportion of students found in Baseerah International School and International Modern Arab School (IMAS).

Table 3. Proportion of Gender in Both Schools

\begin{tabular}{|l|l|l|}
\hline S/N & Gender & Proportion (\%) \\
\hline & Baseerah International School (BIS) and \\
\hline 1 & Male & 58 \\
\hline 2 & Female & 42 \\
\hline & International Modern Arab School (IMAS). \\
\hline 1 & Male & 55 \\
\hline 2 & Female & 45 \\
\hline
\end{tabular}

Furthermore, the paper assesses the rank of a standard public or private school library is expected to have as recommended by the related research. Hence, some of the positions can be overlooked, but librarian officer and security are the recommended positions expected of any library to have (See Table 4).

Table 4. Formal Positions in Public or Private Library

\begin{tabular}{|l|l|l|l|}
\hline S/No & Rank & $\begin{array}{l}\text { Baseerah International } \\
\text { School (BIS) and }\end{array}$ & $\begin{array}{l}\text { International Modern Arab } \\
\text { School (IMAS). }\end{array}$ \\
\hline 1 & Librarian & Yes & Yes \\
\hline 2 & Senior Librarian & No & No \\
\hline 3 & Principal Librarian & No & No \\
\hline 4 & Library Officer & Yes & Yes \\
\hline 5 & $\begin{array}{l}\text { Senior Library } \\
\text { Officer }\end{array}$ & No & No \\
\hline 6 & $\begin{array}{l}\text { Principal Library } \\
\text { Officer }\end{array}$ & Yes & Yes \\
\hline 7 & Security & Yes & Yes \\
\hline
\end{tabular}

Furthermore, the paper presents a positive impact by deploying Koha ILS (See table 5) by identifying the number of devices found in the selected school libraries.

Table 5. IT Gadgets Integrated with the Proposed Koha Application

\begin{tabular}{|l|l|l|l|}
\hline S/No & IT Gadgets & $\begin{array}{l}\text { Baseerah } \\
\text { International School } \\
(\text { BIS) and }\end{array}$ & $\begin{array}{l}\text { International Modern } \\
\text { Arab School (IMAS). }\end{array}$ \\
\hline 1 & Personal Computers & 5 & 5 \\
\hline 2 & Internetwork & $\begin{array}{l}\text { Internet } \\
\text { LAN }\end{array}$ & $\begin{array}{l}\text { Internet } \\
\text { LAN }\end{array}$ \\
\hline 3 & Photocopying Machine & 1 & 2 \\
\hline 4 & VoIP & 4 with GSM & GSM \\
\hline 5 & Scanner & 1 & 1 \\
\hline 6 & Printer & 3 & 2 \\
\hline 7 & Projector & 1 & 1 \\
\hline
\end{tabular}


Based on the analyzed result, Information technology (IT) gadgets available in the schools can be integrated and deployed on our proposed Koha ILS. This can transform the library activities into an automated application system where a library user login into the Koha software on a personal computer to make a reservation of books and other library resources.

However, the results also present that the open issues noted in both schools using manual library activities include insufficient grants, lack of staff capacity building, maintaining broken facilities, and items to purchase are remain costly. All these issues (mentioned in Table 2) were addressed using the proposed Koha ILS (see section 2).

\section{Conclusion}

In conclusion, both public and private school libraries are encouraged to have better financial support for better management of IT gadgets deployed. Capacity building plays a significant role, and it needs to be enforced by organizing workshops and seminars for staff and students who often use the library. For the Koha ILS application, a group of experts needs to be formed to have frequent discussions on improving the application software in terms of maintenance and backend upgrade. Also, there should be operating system compatibility so that the Koha application can be accessed at runtime.Based on the results, it is recommended to maintain an uninterrupted power supply so that students can remotely access the library network. This power availability will also help in keeping records of all books, journals, and white papers.

\section{References}

1. Uzomba, Emeka Christian, Oluwatofunmi Jesudunni Oyebola, and Anthony Chukwuma Izuchukwu. "The use and application of open source integrated library system in academic libraries in Nigeria: Koha example."Library Philosophy and Practice (2015): 1.

2. Brooke, Tony. "Open source integrated library systems in public libraries."School of Information Student Research Journal 3, no. 2 (2013): 3.

3. Bello, Samuel Akande, and Chioma Nnalu Ezeri. "Globalisation of Library and Information Services: An Assessment of the Level of ICT Deployment in Academic Libraries in Oyo State, Nigeria."Library Philosophy and Practice (2020): 1-20.

4. Chawner, B. (2004). Free/open source software: New opportunities, new challenges. Paper presented at the 12th VALA Biennial Conference Breaking boundaries: Integration \&Interoperability. Retrieved from www.vala. org.au/vala2004/2004pdfs/33chawn.pdf

5. Mohideen, Zainab Ajab, Arslan Sheikh, Kiran Kaur, and Muzammil Tahira. “Acceptance of Koha Open Source System among Librarians in the Malaysian Academic Libraries: An Exploratory Qualitative Study." Serials Review (2019): 1-10.

6. Moyo, Lesley M. "Electronic libraries and the emergence of new service paradigms." The Electronic Library (2004).

7. Makori, Elisha Ondieki, and Norak Mauti Osebe. "Koha enterprise resource planning system and its potential impact on information management organizations." Library Hi Tech News (2016).

8. Saffady, William. "The status of library automation at 2000." Library technology reports 36, no. 1 (2000): 7.

9. Ahmed, Muhammed, Aisha Abdalla Hashim, Othman O. Khalifa, Abdulkadir H. Alkali, Nur Bt Midi, and Faridah Abd Rahman. "Evaluating Mobility Management Models for Content Forwarding in Named Data Networking Environments." (2019): 47-60.

10. Ahmed, Muhammed Zaharadeen, Afaf Mirghani Hassan, Abdulkadir H. Alkali, Aisha Hassan Abdallah Hashim, Othman Omran Khalifa, and Huda Adibah Bt Mohd Ramli. "Performance Evaluation of Scenerio-aware Protocol for Producer Mobility Support in NDN." In 2019 7th International Conference on Mechatronics Engineering (ICOM), pp. 1-6. IEEE, 2019.

11. Ahmed, Muhammed Z., Othman O. Khalifa, Aisha Hassan, Abdallah Hashim, Momoh-Jimoh E. Salami, and Muhanad Babikier. "Queuing Theory Approach for Evaluating Rate of Transmission in Wireless Network Using Network Coding.” (2017).

12. Khalifa, Othman O., Aisha-Hassan A. Hashim, and Abdulhakam AM Assidiq. "Vision-based lane detection for autonomous artificial intelligent vehicles." In 2009 IEEE International Conference on Semantic Computing, pp. 636- 641. IEEE, 2009.

13. Ahmed, Muhammed Zaharadeen, Aisha Hassan AbdallahHashim, Othman Omran Khalifa, and Momoh JE Salami. "Border Gateway Protocol to provide failover in multihoming environment."International Journal of Information Technology 9, no. 1 (2017): 33-39. 
14. Babiker, Mohanad, Othman O. Khalifa, Aisha HA Hashim, Momoh-Jimoh E. Salami, and Muhammed Z. Ahmed. "Performance of Turbo Code in CDMA under AWGN Channel." (2017).

15. Babiker, Mohanad, Othman O. Khalifa, Kyaw Kyaw Htike, Aisha Hassan, and Muhamed Zaharadeen. "Automated daily human activity recognition for video surveillance using neural network." In 2017 IEEE 4th International Conference on Smart Instrumentation, Measurement and Application (ICSIMA), pp. 1-5. IEEE, 2017.

16. Babiker, Mohanad, Othman O. Khalifa, Kyaw Kyaw Htike, Aisha Hassan, and Muhamed Zaharadeen. "Harris corner detector and blob analysis featuers in human activty recognetion." In 2017 IEEE 4th International Conference on Smart Instrumentation, Measurement and Application (ICSIMA), pp. 1-5. IEEE, 2017

17. Muhammed Zaharadeen Ahmed, Aisha Hassan Abdalla Hashim, Afaf Mirghani Hassan, Othman O. Khalifa, Abdulkadir H. Alkali, Abubakar Modibbo Ahmed. "Performance Evaluation of Best Route and Broadcast Strategy for NDN Producer's Mobility” International Journal of Engineering and Advanced Technology (IJEAT) ISSN: 2249 - 8958, Volume-9, Issue-1, October 2019

18. Hasan, Mohammad K., Rashid A. Saeed, Aisha-Hassan A. Hashim, Shayla Islam, Raed A. Alsaqour, and Tariq A. Alahdal. "Femtocell network time synchronization protocols and schemes." Research Journal of Applied Sciences, Engineering and Technology 4, no. 23 (2012): 5136-5143.

19. Khalifa, Othman O., Yusnita binti Yusof, Aisha-Hassan Abdalla, and R. F. Olanrewaju. "State-of-theart digital watermarking attacks." In 2012 International Conference on Computer and Communication Engineering (ICCCE), pp. 744-750. IEEE, 2012.

20. Rahman, Arafatur, Saiful Azad, Farhat Anwar, and Aisha Hassan Abdalla. "A simulation-based performance analysis of reactive routing protocols in wireless mesh networks." In 2009 International Conference on Future Networks, pp. 268-272. IEEE, 2009.

21. Musa, Abdulwaheed, Saad Osman Bashir, and Aisha Hassan Abdalla. "Review and Assessment of Electromagnetic Wave Propagation in Sand and Dust Storms at Microwave and Millimeter Wave Bands---Part I.” Progress In Electromagnetics Research 40 (2014): 91-100.

22. Alawi, Mahmoud A., Rashid A. Saeed, and Aisha A. Hassan. "Cluster-based multi-hop vehicular communication with multi-metric optimization.” In 2012 International Conference on Computer and Communication Engineering (ICCCE), pp. 22-27. IEEE, 2012.

23. Musa, Abdulwaheed, Saad Osman Bashir, and Aisha Hassan Abdalla. "Review and assessment of electromagnetic wave propagation in sand and dust storms at microwave and millimeter wave bands--Part II.” Progress In Electromagnetics Research 40 (2014): 101-110.

24. Ahmed, Muhammed Zaharadeen, Afaf Mirghani Hassan, Abdulkadir H. Alkali, Aisha Hassan Abdallah Hashim, Othman Omran Khalifa, and Huda Adibah Bt Mohd Ramli. "Performance Evaluation of Scenerio-aware Protocol for Producer Mobility Support in NDN.” In 2019 7th International Conference on Mechatronics Engineering (ICOM), pp. 1-6. IEEE, 2019.

25. Zainab Ajab, Mohideen. "Librarians' acceptance of open source Library Information System using the Osis-Utaut Model/Zainab Ajab Mohideen.” PhD diss., University of Malaya, 2017.

26. Senan Shayma, Aisha Hassan Abdalla Hashim (2017). Performance aAnalysis of HRO-B+ scheme for the nested mobile networks using OPNet. Indonesian Journal of Electrical Engineering and Computer Science, 8 (2). , 0 pp. 522-532.

27. Mohammad Kamrul Hasan, Musse Mohamud Ahmed, Zuriati Janin, Sheroz Khan, Aisha-Hassan Abdalla, Shayla Islam. (2019). Communication Delays in WAMS in Digital Smart Grid Applications. Indonesian Journal of Electrical Engineering and Computer Science. (p-ISSN: 25024752, e-ISSN: 2502-4760). [Scopus (Q3), Impact Factor (IF): 0.24]

28. Ahmed S.A. Badawi, Nurul Fadzlin Hasbullaha, Siti Hajar Yusoff, Aisha Hassan Abdalla Hashim (2019). Energy and power estimation for three different locations in Palestine. Indonesian Journal of Electrical Engineering and Computer Science, 14 (3)., 0 pp. 1049-1056. . (p-ISSN: 2502-4752, e-ISSN: 2502-4760). [Scopus (Q3), Impact Factor (IF): 0.24]

29. Muhammed Zaharadeen Ahmed, Aisha Hassan Abdalla Hashim, Huda Adibah Bt Mohd Ramli, Kaloma Usman Majikumna. "Evaluating Average Throughput For Quantity Of Data Stream In An Ndn Rendezvous Server". International Journal of Advanced Science and Technology Vol. 29, No. 6, (2020), pp. 125-134 125 ISSN: 2005-4238 IJAST Copyright (C) 2020 SERSC

30. Jabeen, Sumaira, Shabir Hussain, and Shabir Ahmed Ganaie. "An Outline on Practicing Integrated Library System (KOHA)(special Emphasis on College Libraries).” Library Philosophy and Practice (2020): 1-10.

31. Kumar, Vimal. "Application Of Koha In Libraries Of The Indian Subcontinent.” Indkoha. ISBN-13: 978-81-908459-7-7 
32. Mathar, Taufiq, Andi Marwansyah, and Feri Ardinata. "Experiences of UIN Alauddin Library Data Migration from the Old System to A New One." Literatify: Trends in Library Developments 1, no. 1 (2020): 1-7.

33. Asfand-E-Yar, Muhammad, and Ramis Ali. "Semantic Integration of Heterogeneous Databases of Same Domain Using Ontology.” IEEE Access 8 (2020): 77903-77919.

34. Muhammed Zaharadeen Ahmed, Aisha Hassan Abdalla Hashim, Huda Adibah Ramli, Othman O. Khalifa, Abdulkadir H. Alkali, Zainab Mohammed Adamu "Simulation of Handoff Algorithm for NDN Producer's Mobility. Journal od Advance Research in Dynamical \& Control Systems, Vol. 12, Issue-02, 2020 .

35. Nagpal, Ritu, and N. Radhakrishnan. "An evaluative study of Koha, Coral and Vu Find: An open source software." (2019). 